\title{
A NOVA CLASSIFICAÇÃO BRASILEIRA DE OCUPAÇÕES anotações de uma pesquisa empírica
}

\author{
Nelson Hideiki Nozoe \\ ana Maria Bianchi \\ ana Cristina Ablas Rondet
}

\begin{abstract}
Resumo: Abordagem da revisão da classificação brasileira de ocupações (CBO), recentemente promovida pelo Ministério do Trabalho e Emprego, em parceria com algumas instituições de pesquisa, entre as quais a Fundação Instituto de Pesquisas Econômicas (Fipe) da USP. A discussão apresenta uma breve caracterização do contexto em que ocorreram as mudanças por que passou o mercado de trabalho brasileiro nas últimas décadas. Palavras-chave: classificação brasileira de ocupações; ocupações; famílias ocupacionais.
\end{abstract}

Abstract: A survey of the revision of the Brazilian Classification of Occupations (CBO), recently carried out by the Ministry of Labor and Employment, in partnership with research institutions, among them Fundação Instituto de Pesquisas Econômicas (Fipe) of the University of São Paulo. The discussion presents a brief description of the changes in the Brazilian labor market in recent decades.

Key words: Brazilian Classification of Occupations; occupational clusters.

A atividade de revisão da Classificação Brasileira de Ocupações foi conduzida no âmbito da Comissão Nacional de Classificação, sob a coordenação do Ministério do Trabalho e Emprego - MTE. Em articulação com o IBGE - Instituto Brasileiro de Geografia e Estatística, reviu-se a classificação das ocupações brasileiras tendo em vista sua compatibilização com a classificação internacional de ocupações (CIUO 88), definida pela Organização Internacional do Trabalho. Para dar conta da tarefa, o MTE estabeleceu parcerias com algumas instituições brasileiras dedicadas à pesquisa socioeconômica, entre as quais a Fipe - Fundação Instituto de Pesquisas Econômicas, da Universidade de São Paulo. ${ }^{1}$

As páginas que se seguem relatam a experiência da Fipe na empreitada de revisão da CBO. A discussão está organizada em três partes principais: na primeira delas caracterizaremos brevemente o contexto em que ocorreram as mudanças por que passou o mercado de trabalho brasileiro nas últimas décadas; na sessão seguinte descreveremos o conjunto de famílias ocupacionais e ocupações revistas pela Fipe, bem como o método adotado na coleta e atualização dos dados referentes às mesmas; na terceira sessão focalizaremos o ciclo de vida das ocupações, segundo os grandes grupos de famílias ocupa- cionais. Fecharemos o artigo com algumas considerações finais, decorrentes da análise empreendida nas sessões anteriores.

\section{O CONTEXTO}

Nas últimas décadas, o mercado de trabalho brasileiro viu-se submetido a intenso processo de mudanças econômicas, culturais, sociais e políticas, cujas manifestações se fizeram visíveis no âmbito da estrutura das ocupações, dos requerimentos de recrutamento e contratação de profissionais, da condição e vínculos de exercício profissional e das funções desempenhadas sob dada denominação ocupacional.

Tais mudanças, mais acentuadas nos dois últimos lustros do século findo, têm sido relacionadas a uma gama variada de fatores, dentre os quais sobressaem a introdução de novas tecnologias - em especial da informática e internet -, a adoção de novas modalidades de organização produtiva e de gestão, a abertura de mercados nacionais ao capital estrangeiro, o aumento da concorrência interna e o declínio do desempenho econômico do país. ${ }^{2}$ Como sabido, tais fenômenos levaram à adoção de medidas técnicas e administrativas de contenção de custos, por 
sua vez determinantes de redução do nível de emprego e dos postos formais de trabalho.

O resultado desse amplo conjunto de transformações foi o aumento na discrepância entre a Classificação Brasileira de Ocupação - CBO, publicada em 1994, e a realidade de nosso mercado de trabalho. Como qualquer classificação, trata-se de um documento mediante o qual se pretende reconhecer, nomear e codificar os títulos e descrever as características das ocupações do mercado de trabalho. No Brasil, a CBO é utilizada na codificação do emprego do mercado de trabalho. Seu código ocupacional é a chave de identificação do emprego, juntamente com a Classificação Nacional de Atividade Econômica - CNAE e da natureza jurídica dos estabelecimentos. O MTE utiliza esses códigos na Relação Anual de Informações Sociais - Rais, no Cadastro Geral de Empregados e Desempregados - Caged, no Seguro-Desemprego, dentre outros registros administrativos, e no controle da imigração. Ademais, a CBO é usada no rastreamento de vagas dos Serviços de Intermediação de mão-de-obra, na elaboração de currículos e no planejamento da educação profissional. No setor público, porém fora do âmbito desse ministério, é utilizada nas estatísticas de mortalidade do Ministério da Saúde e na identificação da ocupação no Imposto de Renda Pessoa Física - IRPF pela Secretaria da Receita Federal.

Desde a edição pioneira de 1982, a CBO viu-se submetida a alterações pontuais, sem modificações estruturais e metodológicas de monta. A decisão de submetê-la a uma revisão, de sorte a torná-la mais consentânea com a realidade do mercado de trabalho, foi tomada em fins dos anos 90, e o produto desse esforço foi dado a público no último ano findo. Além da revisão e atualização completa de seu conteúdo, a edição 2002 faz uso de uma nova metodologia de classificação. Esta versão contém as ocupações do mercado brasileiro, organizadas e descritas por famílias ocupacionais - também denominadas grupos de base -, cada uma delas correspondente a um conjunto de ocupações similares que integram um domínio de trabalho mais amplo do que aquele da ocupação.

O trabalho de modernização da $\mathrm{CBO}$ contou, em sua etapa de descrição, com a participação de quatro entidades, dentre as quais inclui-se a Fipe. O presente artigo pretende resgatar, ainda que superficialmente, alguns aspectos julgados relevantes da participação da Fundação Seade nesta experiência inovadora e de profunda importância para os estudiosos de nosso mercado de trabalho, administradores de recursos humanos e gestores e formuladores de políticas trabalhistas.

\section{FAMÍLIAS OCUPACIONAIS E OCUPAÇÕES DESCRITAS PELA FIPE}

A Fipe responsabilizou-se pela descrição de 181 famílias ocupacionais, número equivalente a pouco menos de um terço do total de famílias da nova versão da CBO. Mediante aquelas famílias previa-se dar conta da descrição de 636 ocupações. A Tabela 1 discrimina os grandes grupos em que se enquadram as diferentes famílias ocupacionais constantes da CBO.

De acordo com a Tabela 1, pode-se verificar que as ocupações descritas pela Fipe distribuíram-se por oito dos

TABELA 1

Distribuição das Famílias Ocupacionais e Ocupações Descritas pela Fipe, segundo Grandes Grupos

Brasil - 2002

\begin{tabular}{|c|c|c|c|c|}
\hline \multirow{2}{*}{ Grandes Grupos } & \multicolumn{2}{|c|}{ Familias Ocupacionais } & \multicolumn{2}{|c|}{ Ocupações } \\
\hline & №s Absolutos & $\%$ & №s Absolutos & $\%$ \\
\hline Total & 181 & 100 & 636 & 100 \\
\hline \multicolumn{5}{|l|}{ 1. Membros Superiores do Poder Público, Dirigentes de Organizações de } \\
\hline Interesse Público e de Empresas, Gerentes & 36 & 20 & 135 & 21 \\
\hline 2. Profissionais das Ciências e das Artes & 26 & 14 & 109 & 17 \\
\hline 3. Técnicos de Nível Médio & 42 & 23 & 119 & 19 \\
\hline 4. Trabalhadores de Serviços Administrativos & 15 & 8 & 68 & 11 \\
\hline 5. Trabalhadores dos Serviços, Vendedores do Comércio em Lojas e Mercados & 36 & 20 & 131 & 20 \\
\hline 7. Trabalhadores da Produção de Bens e Serviços Industriais & 9 & 5 & 43 & 7 \\
\hline 9. Trabalhadores em Serviços de Reparação e Manutenção & 5 & 3 & 8 & 1 \\
\hline 10. Membros das Forças Armadas, Policiais e Bombeiros Militares & 12 & 7 & 23 & 4 \\
\hline
\end{tabular}

Fonte: Fipe. 
dez Grandes Grupos de famílias que estruturam a CBO 2002, com acentuada concentração nos grupos 3 (Técnicos de Nível Médio), 5 (Trabalhadores dos Serviços, Vendedores do Comércio em Lojas e Mercados), 1 (Membros Superiores do Poder Público, Dirigentes de Organizações de Interesse Público e de Empresas, Gerentes) e, em menor grau, 2 (Profissionais das Ciências e das Artes). ${ }^{3}$ Ficaram de fora, tão-somente, os grupos concernentes às famílias que albergam ocupações rurais, incluídas as extrativas e industriais. Em ambos os casos, todavia, a instituição encarregou-se da descrição das ocupações referentes aos cargos de direção e gerência.

No tocante àqueles descritos, verifica-se que a Fipe teve sob sua responsabilidade parcela importante de alguns grandes grupos. Assim, no Grande Grupo 0 (Membros das Forças Armadas, Policiais e Bombeiros Militares), a fundação descreveu mais de três quartos das 13 famílias; a participação correlata no caso do Grande Grupo 4 (Trabalhadores de Serviços Administrativos) situou-se em torno dos dois terços: 14 das 21 famílias do grupo. Os fatos relatados neste capítulo dizem respeito, portanto, à descrição das famílias mencionadas, atividade levada a cabo entre maio de 2000 e o segundo semestre de 2002.

Previamente à realização da atividade de descrição propriamente dita, os integrantes da equipe da Fipe foram treinados no método Dacum, em fins de fevereiro e início de março de $2000 .^{4}$

O processo de descrição das famílias ocupacionais pelos facilitadores teve como ponto de partida o estudo do escopo, atividade realizada a partir dos arquivos magnéticos disponibilizados pelo MTE ao final da primeira fase do Projeto de Modernização da CBO. Nessa etapa, iniciada em 1996 e completada três anos depois, foi reunida a documentação primordial para o trabalho das entidades conveniadas, a saber:

- Nomenclatura da nova CBO, com cerca de 600 famílias ocupacionais. Reagrupa as ocupações e os sinônimos da CBO94, bem como as novas ocupações e títulos surgidos posteriormente. Elimina ocupações e sinônimos totalmente extintos e ocupações que se transformaram em atividades de uma nova ocupação;

- Revisão do índice ampliado, também conhecido como sinônimos, com cerca de 30 mil títulos;

- Descrição sumária, em caráter provisório, redigida a partir de fontes secundárias (CBO/94, CIUO/88, dentre outros).

Nessa documentação era possível obter uma descrição sumária de cada família ocupacional, o rol de ocupações nela contemplado e, para cada ocupação, os respectivos sinônimos. No que concerne às famílias trabalhadas pela Fipe, a documentação oriunda da primeira fase do Projeto de Modernização antecipava a inclusão de 143 ocupações na nova CBO e a supressão de outras 46 que figuravam da versão de $1994 .{ }^{5}$ Estas foram mantidas apenas para fins de composição da série histórica. Dentre as ocupações incorporadas, quase a metade enquadra-se no Grande Grupo 1, justamente aquele onde também se verificou a maior parcela de supressões. Apenas na família dos $D i$ retores Gerais (1210), foram suprimidas 35 ocupações, o equivalente a mais de três quartos daquele total. No decorrer do estudo de escopo, todavia, nem todas essas mudanças viram-se corroboradas. Assim, ocupações como as de Corretor Especializado em Locais para Antenas (site acquisitor) e de Remarcador acabaram por ficar de fora da CBO 2002, apesar de constarem da documentação da primeira etapa do Projeto de Modernização da CBO. Ademais, durante as investigações que precederam a realização dos painéis, bem como durante a sessão de descrição, novas mudanças no mercado de trabalho acabaram sendo identificadas.

Pelo que ficou dito acima, pode-se verificar que esse material constituiu um conjunto fundamental de informações, que balizou o trabalho de rastreamento dos profissionais a serem convidados para integrar os comitês de especialistas, permitiu identificar o aparecimento de ocupações próximas (parentes) e, no caso de empresas, orientar os responsáveis pelas sessões do pessoal ou de recursos humanos na indicação dos empregados. Para as ocupações formais, seu uso foi complementado com os dados da RaisIdentificada, que propicia conhecer, para cada ocupação, o número de postos de trabalho existentes em determinada empresa, bem como seu endereço. Os dados da Rais permitem verificar, por exemplo, a distribuição espacial das ocupações no território brasileiro e, assim, garantir certo grau mínimo de representatividade regional. ${ }^{6}$

O estudo dos escopos das famílias ocupacionais foi realizado mediante entrevistas em empresas, órgãos e associações de classe e os próprios profissionais. Também os informes disponíveis na internet foram amplamente consultados nesta fase do trabalho.

Uma vez concluído o estudo do escopo, seguia-se o extenuante processo de agendamento dos especialistas. Em média, a presença de um especialista envolveu aproximadamente dez tentativas frustradas. Grande parte da dificuldade adveio da duração das reuniões, que se estendia normalmente por dois dias, e do fato de tratar-se de ativi- 
dade não remunerada para os especialistas convocados. No caso de algumas famílias do Grande Grupo 1, especialmente aquelas referentes aos cargos de Diretores e Gerentes, buscou-se reduzir a duração das reuniões mediante o uso de "descrições-tronco". Este recurso consiste em detalhar, em sessões de apenas um dia, uma matriz Dacum com as competências e habilidades gerais e comuns àqueles cargos, elaborada a partir de um conjunto de gráficos obtidos pelo método convencional. Em situações de absoluta inviabilidade, por exemplo, dos Diretores Gerais (1210), as reuniões foram substituídas por entrevistas (no mínimo cinco) no próprio local de trabalho, de duração variável. Em tais ocorrências, o painel de validação não foi realizado. A implementação de ambos os procedimentos ocorreu sob supervisão e orientação do MTE.

Os óbices enfrentados no agendamento dos profissionais vinculados ao setor bancário requereram um longo esforço, do qual resultou a formação de uma comissão constituída sob os auspícios da Assessoria de Recursos Humanos da Febraban e integrada por representantes dos indicados por alguns estabelecimentos bancários, pelo MTE e pela Fipe. ${ }^{7}$ As dificuldades no agendamento estiveram relacionadas, de um lado, ao zelo com o sigilo que normalmente cercam as operações bancárias. Além disso, o setor sofreu, durante a segunda metade dos 1990, um intenso processo de fusão e mudança de controlador, fenômeno marcado por uma ampla privatização e por maciço ingresso de capital estrangeiro. Por fim, somou-se o fato de ser o segmento financeiro, em especial o bancário, aquele para o qual a antiga $\mathrm{CBO}$ se mostrava profundamente inadequado: cerca de dois quintos de suas informações ocupacionais na Rais, obrigatoriamente fornecidas em consonância com a $\mathrm{CBO}$, eram enquadradas na categoria outros (antigo código 90).

A comissão formada junto à Febraban com o objetivo de diminuir esse descompasso incumbiu-se de avaliar a estrutura de títulos das famílias ocupacionais específicas do setor bancário, suas ocupações e sinônimos, compatibilizar os títulos de cargos dos bancos participantes em postos e ocupações da CBO94 e a nova CBO. Deste esforço resultou uma consolidação preliminar dos títulos de cargos dos bancos participantes, classificados segundo cinco domínios - seguros, crédito, comercial, câmbio e mercado de capitais -, cuja descrição foi majoritariamente colocada sob a responsabilidade da Fipe.

Ao se iniciar a segunda etapa do projeto de modernização da CBO, já com a participação da Fipe, os títulos foram novamente consolidados e reclassificados, desta feita a partir da nova estrutura da CBO. Obtiveram-se, assim, dois conjuntos de famílias ocupacionais: um concernente àquelas específicas e outro pertinente às transversais do setor bancário. O primeiro conjunto ficou formado por 7 e o segundo, por 5 famílias, distribuídas pelos quatro primeiros Grandes Grupos da CBO 2002. ${ }^{8}$ Ao término dessa tarefa, tais famílias passaram a ser descritas mediante a aplicação do método Dacum. As dificuldades no agendamento foram superadas mediante a convocação dos especialistas de 13 instituições bancárias, por intermédio da Febraban. Mesmo assim, os Diretores Gerais (1210) e os Diretores de Operações de Serviços em Instituição de Intermediação Financeira (1227) acabaram sendo descritos mediante entrevistas. Tais desdobramentos fizeram com que a segunda fase do processo de descrição se alongasse por cerca de dois anos.

Os fatos relatados nos parágrafos precedentes, ao mesmo tempo em que evidenciam algumas modalidades de resistência enfrentadas pelos facilitadores da instituição, permitem aquilatar a magnitude do esforço e da persistência envolvidos na superação das mesmas. A seção seguinte registra as observações colhidas pelos facilitadores no curso das descrições das diversas famílias. A percepção das mudanças ocorridas no mercado de trabalho brasileiro foi acentuada entre os especialistas que participaram dos painéis organizados pela Fipe. A freqüência com que estes profissionais mencionavam a necessidade de "Manterem-se Atualizados", durante a montagem da sua lista de Competências Pessoais constitui evidência cabal do vulto das mudanças a que precisaram adequar-se para permanecer no mercado de trabalho.

A sessão que se segue descreve o ciclo de vida das ocupações, retratando movimentos de extinção e desaparecimento das mesmas.

\section{O CICLO DE VIDA DAS OCUPAÇÕES}

O mundo das ocupações é complexo e altamente dinâmico, permanentemente afetado pelo contexto social e econômico mais amplo e, ao mesmo tempo, capaz de afetar esse próprio contexto. Como os seres vivos, as ocupações parecem estar sujeitas a um ciclo de vida. Elas nascem, crescem, transformam-se e eventualmente declinam e morrem.

No que diz respeito ao mercado de trabalho brasileiro, as grandes transformações pelas quais este vem passando nas últimas décadas refletiram-se diretamente em sua estrutura ocupacional. Enquanto várias ocupações simples- 
mente desapareceram, ou estão a caminho disso, outras vêm sofrendo uma reestruturação de suas funções, que leva à definição de novos perfis profissionais. Esse processo está associado, como já foi visto, às modificações tecnológicas ocorridas na economia, inclusive aquelas que afetam a organização do trabalho dentro de empresas públicas e privadas. De uma maneira geral, estão sendo presenciadas mudanças cuja natureza não é auto-evidente, mas cuja direção é importante entender para a definição de políticas públicas adequadas.

A presente sessão focaliza o ciclo de vida das ocupações, que se exprime na emergência de novas ocupações, na extinção de outras e na transformação de muitas. As informações em que se baseia a análise provêm, como observado anteriormente, de depoimentos colhidos entre os especialistas que colaboraram na pesquisa da Fipe, em três momentos sucessivos: durante o trabalho preliminar de definição do escopo de cada família, no painel de descrição e no de validação.

O conceito de ocupação emergente foi definido de forma ampla e não necessariamente isenta de ambigüidades. Assim, as ocupações qualificadas como tal podem ser efetivamente novas no mercado de trabalho, como seria de se esperar. Abrangem ainda, porém, aquelas que são novas do ponto de vista da $\mathrm{CBO}$; ou aquelas que, embora muito antigas, sofreram transformações substanciais ou viram crescer significativamente o número de postos de trabalho a elas associados; finalmente, podem ser novas apenas no mercado de trabalho brasileiro, mas não no mercado de trabalho mundial como um todo.

A unidade de análise considerada compreende as famílias ocupacionais e as ocupações propriamente ditas. Alguns processos afetam todo o agrupamento profissional, manifestando-se no âmbito da família; outros são mais circunscritos, cingindo-se a ocupações específicas dentro de uma família ocupacional, sem afetar de modo significativo as demais categorias que a compõem.

A ordem adotada para a exposição segue a seqüência dos Grandes Grupos definidos pela CBO 2002. Para cada um desses grandes conjuntos, serão abordadas simultaneamente as famílias e ocupações em processo de extinção e as emergentes.

Dentre as ocupações classificadas na nova Classificação Brasileira de Ocupações (CBO) como pertencentes ao Grande Grupo 1, ou seja, "Membros Superiores do Poder Público, Diretores de Organizações de Interesse Público e de Empresas e Gerentes", existem poucas ocupações realmente novas. No entanto, dada a reestruturação por que vêm passando diversas empresas, principalmente no setor privado, muitas delas extinguem postos de diretoria e gerência, fazendo com que os diretores e gerentes remanescentes acumulem funções diferentes.

Nesse contexto, merece destaque a inclusão de uma nova ocupação na família ocupacional dos Gerentes administrativos, financeiros e de riscos (1421). Trata-se do Gerente de riscos. De acordo com os especialistas presentes ao painel de covalidação, essa ocupação ainda não atingiu no Brasil o nível de importância encontrado em países como os Estados Unidos, onde existe um número significativo de cursos regulares de graduação, pós-graduação e MBA na área do chamado Risk Management. Trata-se, portanto, de uma ocupação em ascensão, que acompanha uma tendência de mercado bastante forte no exterior, embora ainda em fase preliminar de expansão no Brasil.

Cabe acrescentar que muitas vezes o gerente de riscos não ocupa um cargo com esse nome, embora atue como tal. Segundo os especialistas, as funções desse profissional diferem daquelas executadas pelos engenheiros de segurança industrial, de tempos e métodos, de qualidade, de riscos ou dos técnicos de seguros, principalmente no que diz respeito aos compromissos objetivos e mensuráveis a partir dos resultados operacionais da empresa. As atividades desenvolvidas pelo gerente de riscos não se caracterizam como atividades gerenciais por excelência, uma vez que estão mais voltadas às atividades desenvolvidas dentro de um processo produtivo, o que lhes dá um cunho mais executor.

O Grande Grupo 2 ("Profissionais das Ciências e das Artes") reúne ocupações cujas tarefas demandam conhecimentos profissionais de alto nível de competência ligado ao ensino superior, além dos profissionais das artes e desportos. Dentro desse grupo existem diversas famílias ocupacionais que possuem uma ou mais ocupações novas ou em processo de reestruturação.

É o caso, por exemplo, dos Professores de artes do ensino superior (FO 2349), que congregam as seguintes ocupações: Professor de artes do espetáculo, Professor de artes visuais e Professor de música no ensino superior. Embora não possa ser considerada uma família ocupacional emergente, o mercado de trabalho brasileiro tem especificidades que o distinguem do mercado de países onde o ensino superior nessa área está sedimentado há mais tempo. Segundo os especialistas presentes aos painéis de descrição e validação, houve mudanças substanciais em um período relativamente recente no Brasil, com a implementação de 
inúmeros cursos superiores de graduação na área de artes, que compreendem os segmentos de artes visuais, teatro, dança e música. Isso gerou a necessidade de uma rápida e por vezes radical adaptação no perfil dos professores que lecionam nesses cursos. Antigamente, a arte era acessível a poucas pessoas e era ensinada principalmente em ateliês dos próprios artistas. A mudança assinalada afetou esse padrão. Hoje em dia, nem sempre um professor de artes é efetivamente um artista, ele pode ser um especialista em determinada área e com isso qualificar-se para transmitir seus conhecimentos aos alunos.

Merece destaque também a família ocupacional das $\mathrm{Se}$ cretárias executivas e bilíngües (FO2523), que congrega as ocupações de Secretária executiva, Secretária bilíngüe e Secretária trilíngüe. ${ }^{9}$ Segundo o relato dos especialistas, não se observa a tendência de extinção da profissão. Na prática, grande parte das secretárias ainda executa tarefas tradicionais, às vezes atendendo mais de um diretor ou até mesmo toda uma área. Nos últimos anos houve uma diminuição significativa no número de postos de trabalho de secretária nas empresas, devido basicamente a dois motivos: informatização e reestruturação funcional, diante da necessidade de reduzir custos operacionais. Com a difusão dos computadores de uso pessoal, os executivos passaram a executar fácil e rapidamente tarefas antes delegadas às secretárias, cujo perfil profissional sofreu alterações significativas, levando-as a atuar cada vez mais como assessoras do executivo. Isso significa que a profissão foi afetada por um duplo movimento, de diminuição do número de postos de trabalho associada a alguma perda de funções tradicionais, mas, ao mesmo tempo, à absorção de novas funções e à ampliação de responsabilidades.

A família ocupacional dos Locutores, comentaristas e repórteres de rádio e televisão (FO 2617) reúne profissionais cujo perfil apresentou modificações bastante importantes nos últimos anos, que afetaram as ocupações componentes da família: Âncora, Comentarista, Locutor, Narrador e Repórter de rádio e televisão. Como em outros setores da economia, houve uma série de alterações econômicas e tecnológicas, associadas a um processo de reorganização funcional, em que as empresas enxugaram consideravelmente o número de funcionários em seus quadros.

Nesse contexto, a própria definição das atividades precípuas de um Locutor de rádio e televisão mudou substancialmente. Atualmente, as atividades de locução são desempenhadas por jornalistas, que não mais simplesmente lêem as notícias, como no modelo anterior. Eles tornaram-se profissionais multifuncionais e multimídia, para os quais não basta - nem mesmo chega a ser necessário - ter uma bela voz. Eles atuam no processo desde a produção da notícia até sua apresentação. A tendência do mercado é substituir o locutor tradicional por um profissional com formação em jornalismo capaz de atuar indiscriminadamente em rádio, televisão e outros meios de comunicação.

No caso do rádio, as mudanças tecnológicas nos equipamentos utilizados facilitaram a operação de equipamentos. Assim, as tarefas técnicas, como a de operador de transmissões externas no rádio, podem ser hoje também desempenhadas pelo próprio locutor, quando este atua fora da sede da emissora. O advento das rádios FM e das TVs por assinatura também foi um importante fator na indução das mudanças observadas.

Cabe acrescentar que a partir da década de 90 o locutor clássico passou a chamar-se "Âncora”, por influência dos Estados Unidos, onde existia há muito tempo. Essa diferença, que à primeira vista parece indicar uma mera mudança de terminologia, reflete uma transformação mais profunda no perfil profissional dos especialistas que exercem essa função.

No domínio da informática, ainda no Grande Grupo 2, existem diversas ocupações emergentes e em reestruturação. Isso se deve principalmente ao fato de que o mercado de trabalho ligado a esta área ser relativamente novo e encontrar-se em fase de consolidação. Assim, muitos profissionais possuem uma atuação mais abrangente, executando diversas tarefas, padrão que não necessariamente será mantido no futuro próximo.

É o caso, por exemplo, do Web master, profissional responsável pela manutenção de um website, que entende o site de forma global e o administra. É ele quem garante o contato entre as diversas áreas: produção de conteúdo, design, desenvolvimento e manutenção do site. Os especialistas presentes aos painéis relataram que, com o surgimento do ambiente web, muitas vezes este profissional acumulava funções que iam desde a elaboração de textos até o gerenciamento dos sites. No entanto, com a especialização do mercado, as funções foram aos poucos se diferenciando e se tornando mais específicas, embora o web master tenha de certa forma mantido sua característica de programador. Trata-se, portanto, de um profissional relativamente novo no mercado, que exerce funções bastante híbridas e muito variáveis de uma empresa para outra.

Já a figura do Web Designer surgiu com o aparecimento dos recursos visuais dentro do ambiente web. Ele é o responsável pela parte visual dos sites, fazendo inclusive interface com a animação. É ele quem desenha e define 
as cores e o design das páginas ou dos sites. A formação desse profissional tende a ser bastante heterogênea, uma vez que é atualmente integrada por indivíduos com diferentes origens profissionais, entre eles arquitetos, artistas gráficos e profissionais da indústria gráfica, entre outros, que decidiram aproveitar as oportunidades abertas graças ao surgimento do ambiente web.

Finalmente, os especialistas mencionaram a figura do $\mathrm{Web}$ Editor, profissional responsável pelo conteúdo dos textos apresentados nos sites. A maioria deles possui formação em jornalismo, relações públicas ou publicidade, entre outras. Na verdade, observa-se aqui um fenômeno parecido com o que determinou a mudança do perfil do locutor, acima relatada: trata-se de um jornalista que exerce suas funções em um meio de divulgação diferente do usual.

O Grande Grupo 3 ("Técnicos de Nível Médio") compreende aquelas ocupações cujas atividades requerem um nível de conhecimento técnico para sua execução. É interessante notar a presença de indivíduos com formação universitária nesse grande grupo, que reúne um grande número de famílias ocupacionais. Essa presença é crescente, embora, em tese, a execução das atividades não requeira escolaridade de nível superior. Na prática, contudo, observa-se a exigência cada vez maior de formação universitária para preenchimento das vagas oferecidas no mercado de trabalho. Essa exigência pode ser atribuída a uma gama de fatores, inclusive o aumento do nível de desemprego, que leva o indivíduo a aceitar tarefas aquém de sua qualificação formal.

Vale mencionar, a propósito, a existência de três famílias ocupacionais ligadas à educação que vêm passando por uma série de modificações. Aqui existe uma mescla de processos de extinção de ocupações e criação de novas, bastante difícil de descrever. A mudança afeta as famílias dos Professores de nível médio na educação infantil (FO 3311), Professores de nível médio no ensino fundamental (FO 3312) e Professores leigos no ensino fundamental (FO 3321).

As três famílias citadas reúnem professores cuja formação foi adquirida na prática ou em cursos de, no máximo, nível médio, que atuam na educação infantil e no ensino fundamental (antigos primário e ginásio). Houve uma mudança legal segundo a qual, a partir de 2007, somente poderão habilitar-se a preencher os postos de trabalho associados a essas ocupações indivíduos com diploma universitário ou formados por treinamento em serviço. ${ }^{10}$ Isso significa que aqueles que não tiverem concluído o segundo grau até 2007 não poderão continuar lecionan- do. Perante essa exigência, os docentes vêm se atualizando para poder continuar no exercício de suas funções quando da aplicação da nova lei.

O caso dos professores leigos merece destaque, uma vez que são profissionais que não possuem a formação mínima já exigida por lei, o que poderá determinar a extinção dessa categoria. Vale mencionar, porém, que a maioria desses profissionais participa de programas do MEC (como o Proformação - Programa de Formação de Professores em Exercício), cujo objetivo é a formação de professores leigos num nível equivalente ao do magistério. Esses programas beneficiam prioritariamente as Regiões Norte, Nordeste e Centro-Oeste.

A família ocupacional dos Profissionais de direitos autorais e de avaliação de produtos dos meios de comunicação (FO 3524) também sofreu modificações profundas em sua estrutura, que resultaram na convergência de processos de extinção e emergência. Inicialmente, antes do trabalho de definição de seu escopo, foi identificada pelo MTE como a família dos Agentes de Fiscalização de Espetáculos e Meios de Comunicação, composta apenas pela ocupação de Técnico em Censura, tristemente associada ao período da ditadura militar no Brasil. Com a abolição desse tipo de censura, a ocupação deixou formalmente de existir no mercado de trabalho. Persistem, porém, os profissionais que atuam na área de direitos autorais, na fiscalização de espetáculos de música, dança, etc. Por outro lado, os especialistas apontaram a necessidade de orientação do público a partir da definição de faixas etárias para as quais diversos tipos de produtos culturais são adequados. Além dessa tarefa, algumas empresas que atuam nesse segmento sentiram a necessidade de recrutar profissionais incumbidos da avaliação qualitativa do programa, que abrange funções relacionadas à avaliação dos meios de comunicação do ponto de vista ético, educativo e artístico, sendo que os profissionais podem realizar a classificação indicativa e qualitativa da programação.

Os participantes dos painéis destacaram que, enquanto as ocupações de Agente de Direitos autorais e Ouvidor de meios de comunicação (ombudsman) são bem definidas no mercado de trabalho, a ocupação de Avaliador de produtos do meio de comunicação, que define o responsável pela avaliação e classificação, qualitativa e indicativa dos programas, ainda é relativamente nova e encontra-se em fase inicial de estruturação, não estando efetivamente implantada na maioria das empresas.

Um fenômeno interessante foi observado em relação à ocupação de Radiotelegrafista, enquadrada pela CBO 2002 
na família ocupacional dos Operadores de rede de teleprocessamento e afins (FO 3722), ao lado do Operador de rede de teleprocessamento. No período de definição do escopo e na convocação para os painéis, o facilitador teve grande dificuldade de recrutar radiotelegrafistas, tendo de fazê-lo na Região Norte, por intermédio da Funai. Vale notar que na estrutura original da $\mathrm{CBO}$, que balizou a pesquisa do facilitador da Fipe, o título dessa família foi definido como sendo "Técnicos em operação de máquinas de transmissão de dados", prevendo-se que compreendia oito ocupações distintas. Contudo, após a investigação detalhada de sua situação atual no mercado de trabalho, esse número ficou reduzido a dois, sendo que, no caso do radiotelegrafista, observou-se sensível perda de especificidade. Os especialistas presentes aos painéis confirmaram a existência desse processo: embora tenham mantido a ocupação na família, apontaram sua tendência à extinção.

No caso da família ocupacional dos Técnicos em necrópsia e taxidermistas (FO 3281), os especialistas também registraram a ocorrência de uma alteração interessante no perfil das atividades executadas pelos profissionais da área. O título da família ocupacional proposto inicialmente pelo MTE (Embalsamadores e Taxidermistas) foi modificado pelos especialistas no painel de validação. De acordo com o comitê, a alteração justifica-se pelo fato de que o embalsamamento é apenas uma das técnicas de conservação de corpos. Optaram, contudo, por preservar o título de Embalsamador para designar uma das ocupações da família, pois este é o termo utilizado no mercado de trabalho, embora o referido profissional utilize outras técnicas além do embalsamamento. Os especialistas relataram ainda que a ocupação de Embalsamador é hoje pouco expressiva no mercado de trabalho, uma vez que, oficialmente, a atividade deve ser desenvolvida por um médico patologista. O médico é responsável por assinar a liberação do corpo embalsamado, embora, na prática, ele costume ensinar as operações técnicas ao pessoal de apoio, que as executa.

A segunda ocupação que integra a família é a de Taxidermista. A Taxidermia é uma especialização da Biologia, e conta ainda com um pequeno número de profissionais no mercado de trabalho brasileiro. Trata-se de uma atividade auxiliar da biologia, cuja finalidade é a conservação de animais mortos, utilizando somente a pele curtida do exemplar. Existe ainda a Taxidermia Artística e a Científica, desenvolvida em Universidades e Museus, com o objetivo de catalogar espécies para a preservação da história natural.
Cabe ainda ressaltar que, por motivos técnicos, foi eliminado o sinônimo "Empalhador de Animais". De acordo com os especialistas, esse termo é incorreto, pois as técnicas de taxidermia utilizam uma infinidade de materiais além da palha (a que o sinônimo eliminado faz referência) na recomposição do corpo do animal a partir de sua pele.

O Mecânico de vôo, que integra a família ocupacional dos Pilotos de aviação comercial, mecânicos de vôo e afins (FO 3411), é outra ocupação do Grande Grupo 3 que está perdendo expressão no mercado de trabalho em decorrência de mudanças tecnológicas. O profissional com esse tipo de formação e experiência era recrutado apenas para trabalhar nas aeronaves de grande porte. As aeronaves modernas, porém, que possuem computador de bordo, prescindem de seu trabalho. Os raros remanescentes da ocupação têm deixado o País, acompanhando antigos aviões vendidos para outros países, principalmente africanos.

Quanto às ocupações emergentes, cabe mencionar a família ocupacional dos Técnicos de odontologia (FO 3224), que reúne as ocupações de Técnico em higiene dental, Protético dentário, Atendente de consultório dentário e Auxiliar de prótese dentária. O trabalho prévio de definição de escopo e os painéis realizados apontaram o surgimento de uma nova ocupação, o Técnico em higiene dental, que atua majoritariamente em órgãos públicos, sob a supervisão de um cirurgião-dentista.

Durante os trabalhos da fase de descrição da família ocupacional dos Técnicos de seguros e afins (FO 3517), os especialistas presentes ao painel de descrição identificaram uma ocupação emergente, a do Técnico de Inspeção Veicular. De acordo com os participantes, esse profissional pode passar a existir em larga escala no mercado de trabalho num futuro próximo, em função das exigências dos Detran estaduais e das seguradoras de veículos. Trata-se de um profissional que realiza inspeções em veículos que passaram por alterações em sua estrutura original, sofreram sinistros ou foram reformados e, portanto, necessitam de aprovação para transitar. Vale acrescentar, porém, que essa ocupação não foi reconhecida pelo comitê de validação e, portanto, não aparece na versão final da família ocupacional.

Na mesma família, outra ocupação "descoberta" durante os trabalhos, mantida após a validação, foi a do Técnico de Resseguros, que negocia, administra e controla os contratos com o IRB (Instituto de Resseguros Brasil), órgão que possui o monopólio dos resseguros no país. Como 
existem estudos no sentido de quebrar esse monopólio, poderá vir a ocorrer uma expansão dos postos de trabalho ligados a essa ocupação no futuro.

$\mathrm{Na}$ família ocupacional dos Técnicos em secretariado, taquigrafos e estenotipistas (FO 3515), vale destacar que a nova denominação do Estenógrafo, consagrada pelo mercado, na verdade desdobra-se em duas ocupações: o Taquígrafo, que procede manualmente às atividades de registro, tanto no setor público quanto privado (depoimentos, discursos, etc.); e o Estenotipista, cujas atividades refletem o avanço tecnológico na área de comunicações, já que faz uso do computador no exercício de suas funções, possibilitando o registro dos fatos em tempo presente (close caption, mensagens para deficientes auditivos na televisão, atividades que necessitem de legendas).

A família ocupacional dos Acupunturistas, podólogos, quiropraxistas e afins (FO 3221) agrupa duas ocupações já existentes na CBO 94 (Acupunturista e Quiropraxista), ao lado de uma nova ocupação definida no âmbito da nova CBO: o Podólogo. Inicialmente havia sido definida como ocupação também o Técnico em Fisioterapia, que compunha o título da família. No entanto, durante o estudo de escopo, essa denominação mostrou-se inadequada. ${ }^{11}$

$\mathrm{Na}$ verdade, os profissionais que prestam serviços nessa área, em geral conhecidos como atendentes, não são reconhecidos como técnicos em fisioterapia. Entre os motivos alegados destacam-se: o fato de que estes profissionais não possuem formação na área de saúde, tampouco formação específica em fisioterapia; não prescrevem exercícios ou verificam se os mesmos estão sendo realizados corretamente (o que é feito pelo fisioterapeuta). Suas funções consistem apenas em instalar os pacientes em aparelhos específicos, utilizando-os sob constante supervisão; também cuidam da limpeza e organização da clínica. Outra razão que levou à solicitação de exclusão da denominação "técnico em fisioterapia" foi o fato de não ter sido localizada nenhuma instituição de ensino que ministrasse o curso de fisioterapia em nível médio.

Os especialistas que representaram a ocupação dos Podólogos destacaram que sua prática advém da medicina ortodoxa, e seus procedimentos direcionam-se à saúde do pé. Tratam de afecções, infecções, patologias dos pés e deformidades podológicas, utilizando-se de instrumental pérfuro-cortante, medicamentos de uso tópico, órteses e próteses. Com a multiplicação de clínicas especializadas nos grandes centros urbanos brasileiros, há indícios de que essa ocupação venha conquistando um lugar de maior destaque no mercado de trabalho brasileiro.
Ainda dentro do Grande Grupo 3, os Recreadores (FO 3714) constituem uma família ocupacional relativamente nova no mercado, que tende a ser mais valorizada. Segundo os especialistas, isso vem ocorrendo principalmente depois que hotéis e resorts reconheceram a importância desse profissional como diferencial para atrair um maior número de clientes. Apesar de existirem alguns cursos na área - desde cursos técnicos pertencentes ao sistema Senai/ Senac até cursos de graduação em Gestão de Lazer e Eventos -, a maioria dos profissionais não possui formação específica. Nesse sentido, seu nível de escolaridade varia muito, indo desde o segundo grau incompleto até o nível superior, este nem sempre na área específica).

O Grande Grupo 4, "Trabalhadores de Serviços Administrativos", compreende as ocupações ligadas ao trabalho burocrático, com ou sem contato constante com o público.

Dentro desse grande grupo, merece destaque a família ocupacional dos Apontadores e conferentes (FO 4142). No trabalho inicial de definição do escopo, a facilitadora entrevistou vários empresários e diretores de recursos humanos do setor industrial que relataram a extinção da ocupação de Apontador de Produção, decorrente de mudanças tecnológicas. No prosseguimento do trabalho, foi possível constatar que as atividades dessa área foram incorporadas por outras ocupações, porém o redesenho do trabalho, quando da reestruturação produtiva, diferia de empresa para empresa e de setor para setor. Na construção civil, os apontadores de produção e de mão-de-obra são ainda numerosos, e provavelmente ainda o serão por muito tempo. Também permaneciam, segundo os entrevistados, em atividades de apontamento de produção de serviços públicos. Durante a realização dos painéis, verificou-se, de um lado, a tendência ao desaparecimento da ocupação de Apontador (seja de produção, seja de mãode-obra), devido à incorporação de novas tecnologias ao processo produtivo, que levam ao esvaziamento das funções exercidas; de outro lado, porém, os trabalhadores remanescentes vêm acumulando funções tradicionalmente exercidas por trabalhadores de outros cargos. A tendência seria assim a transformação do apontador em um encarregado que tem, entre outras tarefas, a função de apontador de mão-de-obra e/ou de produção.

Ainda nessa mesma família ocupacional, foi incluída uma ocupação inexistente na CBO 94, embora antiga no mercado de trabalho: o Conferente de carga e descarga, que atua na área portuária e anota tudo o que diz respeito ao embarque e desembarque de mercadorias nos portos e 
terminais portuários (avarias, tipo de carga, volume, peso, etc.). Ao conferir, o profissional toma nota e/ou aponta, realizando tarefas muito semelhantes às executadas pelos apontadores, o que justificou sua inclusão nessa família ocupacional.

Entre os Operadores de telefonia (FO 4222), a ocupação de Telefonista propriamente dita encontra-se em processo de extinção, segundo o depoimento dos especialistas e os contatos feitos durante o trabalho prévio de definição de escopo. A tendência da ocupação é desaparecer, devido aos avanços técnicos nos sistemas de telecomunicações. Atualmente, grande parte das ligações é feita diretamente da origem para o destino, sem a necessidade de auxílio de telefonistas. Por outro lado, em empresas pequenas e mesmo em algumas médias, os recepcionistas ou secretários fazem o serviço de atendimento telefônico. Em empresas grandes, os departamentos já possuem ramais diretos e os funcionários fazem e recebem suas próprias ligações. O telefonista fica mais como prestador de informações em casos especiais em que os usuários externos não possuem o número direto do ramal.

Os participantes dos painéis mencionaram outros fatores que estão levando à progressiva extinção da ocupação. Um deles é o serviço de atendimento eletrônico, que está se expandindo muito entre empresas de todos os portes. Nesse caso, os ramais dos departamentos são fornecidos pela gravação. Adicionalmente, foi mencionado o processo de terceirização do atendimento das operadoras telefônicas, como a Embratel e a Telefônica. Tais empresas não possuem mais teleoperadores em seu quadro de funcionários, pois contratam outras empresas para esse serviço, sendo caracterizadas mais como prestadoras de informações do que de completadoras de chamadas. A difusão da internet também provocou mudanças nas ocupações dessa família, pois informações como números da lista telefônica, códigos de área interurbanos e internacionais e tarifas podem ser obtidas diretamente no site da operadora.

É importante registrar o esvaziamento do mercado de muitas ocupações que integram a família ocupacional dos Operadores de equipamentos de entrada e transmissão de dados (FO 4121). Essa família, que na CBO 94 abrigava dez ocupações, agora abriga apenas quatro: Datilógrafo, Digitador, Operador de mensagens de telecomunicações (correios) e Supervisor de digitação e operação. Ocupações que constavam da $\mathrm{CBO}$ 94, ligadas à operação de máquinas de escritório - tais como Conferidor (cartões e fitas), Operador de equipamento de entrada de dados, Operador de máquina contábil, Operador de máquinas classificadoras e tabuladoras e Operador de teleimpressão -, foram eliminadas ou fundidas em função das mudanças tecnológicas no setor, entre elas o advento do computador de uso pessoal. Mesmo algumas das remanescentes, como Datilógrafo e Digitador, vêm perdendo expressão numérica no mercado de trabalho.

O Grande Grupo 5, "Trabalhadores dos Serviços, Vendedores do Comércio em Lojas e Mercados", reúne trabalhadores cujo conhecimento e experiência são utilizados na prestação de serviços (em geral, de proteção e segurança) às pessoas ou na venda de mercadorias no comércio em geral.

$\mathrm{Na}$ família dos Agentes comunitários de saúde e afins (FO 5151) inclui-se uma ocupação emergente, a de Agente comunitário de saúde. Essa ocupação foi criada na década de 90, principalmente por iniciativa do Ministério da Saúde. Os especialistas que exercem a ocupação prestam assistência de saúde em comunidades carentes, entre as quais a dispensa de cuidados simples de saúde sob supervisão de profisssionais do setor, a orientação da comunidade para a promoção da saúde, a participação em campanhas preventivas, o incentivo a atividades comunitárias e assim por diante.

Nota-se também na mesma família ocupacional, a presença de uma ocupação em processo de extinção, que é a Parteira leiga. Muito comum nas zonas rurais brasileiras ainda em meados do século XX, essa profissão entrou em desuso com a difusão dos serviços de saúde e o aumento da possibilidade de acesso das parturientes a hospitais e postos. Segundo as parteiras leigas que participaram dos painéis, a rede pública de saúde está se empenhando em aproveitar seus conhecimentos e habilidades ancestrais no atendimento à comunidade prestado pelos postos e pela rede hospitalar. Elas tornaram-se, portanto, auxiliares da rede oficial de saúde.

Com o declínio da navegação fluvial no Brasil, ocupações tipicamente ligadas a esse setor encontram-se em processo de extinção ou de transformação. Entre elas, destaca-se a ocupação de Taifeiro, que pertence à família dos Trabalhadores de segurança e atendimento aos usuários de transportes (FO 5111). Apesar de essa mesma denominação aparecer como sinônimo em outra família ocupacional (Praças das forças armadas - FO 0103), é na FO 5111 que ela aparece como ocupação propriamente dita. O Taifeiro é o profissional responsável pela organização e controle do paiol (despensa da embarcação), pelo serviço de refeições aos passageiros ou tripulantes, bem como pela limpeza e arrumação das partes internas das 
embarcações. Os especialistas apontaram a ocorrência de uma mudança de ênfase nas funções executadas por esse profissional. Parte de suas funções antigas foi perdida, principalmente no que diz respeito ao atendimento a passageiros e tripulação durante as refeições. Por outro lado, o taifeiro passou a desempenhar um maior número de atividades relacionadas ao controle de alimentos, limpeza e organização dos paióis (paioleiro).

A família ocupacional 5211 congrega os Operadores do Comércio em Lojas e Mercados, integrada por sete ocupações: Vendedor em comércio atacadista, Vendedor de comércio varejista, Promotor de Vendas, Demonstrador de mercadorias, Repositor de mercadorias, Atendente de farmácia (balconista) e Frentista. Nessa categoria também se enquadraria a ocupação de Remarcador do comércio, profissional empregado pelas grandes redes de supermercados para remarcar o preço das mercadorias. Dois motivos explicam a transformação sofrida nas atividades desses especialistas: a difusão do uso de códigos de barras, de um lado, e o arrefecimento da inflação no Brasil, de outro. Com a mudança, as atividades do Remarcador passaram a ser exercidas pelo próprio Repositor de mercadorias.

Em outra família do Grande Grupo 5, observam-se mudanças relacionadas a processos de extinção e emergência de certas ocupações e técnicas. Trata-se da família dos Trabalhadores dos serviços funerários (FO 5165), que congrega uma única ocupação, a do Agente funerário. Os trabalhadores que atuam nessa área trabalham tanto em estabelecimentos privados como nos serviços funerários municipais. Em ambos os casos, vêm procurando atualizar-se em "tanatopraxia", uma moderna técnica de conservação de cadáveres que se vem difundindo inclusive nos serviços municipais. Segundo os especialistas, a tendência é que, aos poucos, os agentes funerários venham a exercer as atividades de Tanatólogo ou Tanatopraxista. O antigo Coveiro, definido como "abridor de covas", acha-se em extinção nos grandes meios urbanos, em face da substituição das covas pelas gavetas, construídas por empreiteiras. Nestas localidades, os coveiros subsistem em cemitérios pertencentes a algumas religiões que adotam outros métodos de sepultamento, como os israelitas. Nas cidades menores, o sepultamento em covas ainda é predominante e, portanto, ainda existe um grande número de coveiros. Vale acrescentar que os especialistas que participaram da descrição não gostavam do vocábulo "coveiro" e, também por isso, insistiram fortemente na sua substituição por sepultadores.

A família ocupacional dos Trabalhadores de serviços veterinários, de higiene e estética de animais domésticos
(FO 5193) inclui um tipo de trabalhador que vem adquirindo importância cada vez maior no mercado de trabalho, segundo os especialistas que participaram dos painéis. As exposições de animais de pequeno porte estão se tornando mais freqüentes no país, e exigem os serviços do Esteticista de animais domésticos, que se torna cada vez mais requisitado, inclusive em decorrência do maior vulto da criação doméstica de cães, gatos e outros animais. A proliferação das chamadas petshops no Brasil também vem demandando um número crescente de Banhistas e Tosadores, treinados nas tarefas de banho e tosa, respectivamente, de animais domésticos. Tais profissionais adquirem seu desenvolvimento profissional na experiência de trabalho e em cursos de especialização.

O Supervisor de Lavanderia, pertencente à família ocupacional dos Supervisores de lavanderia (FO 5102), também pode ser considerado uma ocupação emergente no mercado de trabalho. A demanda por esse profissional reflete o crescimento das empresas especializadas em lavagem de roupa, setor no qual se nota um processo rápido e intenso de terceirização de atividades. De acordo com os especialistas que participaram dos painéis, a tendência é de que esse tipo de empresa cresça ainda mais nos próximos anos e, com ela, a ocupação mencionada. ${ }^{12}$

A família ocupacional dos Catadores de material reciclável (FO 5192) também pode ser incluída entre as ocupações emergentes, senão pela natureza da ocupação propriamente dita, pelo menos por sua expressão numérica no Brasil de hoje, pelas mudanças tecnológicas associadas ao exercício da profissão e, principalmente, pela forma de organização do trabalho. Os catadores ainda congregam, em sua maioria, trabalhadores autônomos, que trabalham por conta própria. Segundo relatado no painel de descrição, muitos desses trabalhadores são antigos moradores de rua que foram treinados para a ocupação. Entretanto, vem ocorrendo um movimento de organização desses profissionais em associações do tipo cooperativas, como meio de melhorar sua renda, suas condições de trabalho e sua capacitação profissional. Assim, funções tipicamente encontradas nas cooperativas, tais como pesador, balanceiro, rasgador de saco, enfardador, separador e triador, que antes eram de responsabilidade dos empregados dos donos de ferro velho, hoje são crescentemente exercidas pelos próprios catadores no interior das cooperativas.

Quanto ao Grande Grupo 6 ("Trabalhadores Agropecuários, Florestais e da Pesca"), a Fipe não foi responsável pela descrição ou validação de nenhuma família ocupacional pertencente a essa categoria. 
O Grande Grupo 7 ("Trabalhadores da Produção de Bens e Serviços Industriais”) compreende as ocupações da construção civil, da produção extrativa e da produção industrial em geral. Dentro dessa categoria, destacam-se duas famílias ocupacionais descritas pela Fipe e que apresentam modificações no perfil de suas ocupações. Tratase dos Condutores de veículos sobre trilhos e cabos aéreos (FO 7826) e dos Trabalhadores em manobras de transportes sobre trilhos (FO 7831).

A primeira dessas famílias compreende seis ocupações: Operador de trem de metrô, Maquinista de trem, Maquinista de trem metropolitano, Motorneiro, Auxiliar de maquinista de trem e Operador de teleférico (passageiros). As atividades exercidas pelo Operador de trem de metrô, embora não sejam novas, vêm sofrendo alterações. Como atualmente a condução do metrô é feita de forma automática, o operador passou a ter como função principal a monitoração do sistema e do painel de falhas. Suas atividades consistem na identificação de sinais e em providenciar soluções para as falhas. Ele só passa a operar manualmente a composição quando o sistema automático não funciona. O mesmo processo ocorre com o Maquinista de trem: graças a mudanças tecnológicas na operação dos equipamentos, o profissional dessa área, cujas atividades caracterizavam-se antes como mecânicas, foi transformado em operador de sistemas automatizados.

$\mathrm{Na}$ categoria dos trabalhadores de manobras sobre trilhos, as ocupações da família ocupacional foram reestruturadas, restringindo-se hoje a apenas duas: Manobrador e Agente de pátio. Simultaneamente, houve a extinção de algumas ocupações, expressas na alternância das funções de Manobrador e Maquinista. Em outras palavras, Maquinistas e Manobradores são atualmente escalados para exercer ambas as funções em períodos alternados. O mesmo processo ocorre com os Agentes de Pátio, que, além de exercerem as atividades intrínsecas de sua função, tais como a liberação de trens para partida, o controle de cargas e o controle de entrada e saída de trens do pátio, são escalados também para executar atividades de manobras dos trens. Parece assim repetir-se o fenômeno apontado para muitas ocupações aqui analisadas: a tendência ao recrutamento de profissionais polivalentes capazes de atuar em várias frentes ao mesmo tempo.

\section{CONSIDERAÇÕES FINAIS}

Este artigo buscou registrar, e assim preservar, alguns aspectos relacionados à descrição, pela Fipe, de alguns grupos de base da CBO 2002. A riqueza dos detalhes observados deu ao mesmo um caráter necessariamente descritivo, mas a brevidade do tempo disponível e a recentidade dos fatos examinados impedem que as colocações nele expostas sejam encaradas como completas e definitivas. Apenas os aspectos mais proeminentes relacionados ao mercado de trabalho foram aqui considerados. Seria por isso por demais ocioso repeti-los aqui.

Pelo fato das informações estarem fundamentadas na experiência específica da Fipe, e por se tratar de uma tarefa realizada a partir de um método de natureza eminentemente qualitativa, parece oportuna a sugestão de dar prosseguimento à pesquisa, com o intuito de verificar a validade das afirmações expostas ao longo do texto à luz de dados de caráter quantitativo. Nesse sentido, os informes levantados na PNAD e/ou na Rais poderiam ajudar a compor um quadro mais completo.

É importante reconhecer, mais uma vez, a importância do trabalho de modernização da CBO levado a cabo pelo MTE com a colaboração de quatro entidades externas, conforme relatado em MTE/SPPE 2002. É sabido que a padronização da linguagem é elemento central quando se trata de informação da gestão pública. A elaboração de políticas públicas consistentes com a nossa realidade socioeconômica depende da qualidade da informação que recebem seus formuladores. Especificamente na gestão das políticas de emprego e de formação do trabalhador brasileiro, tal adequação fica condicionada à disponibilidade de informações padronizadas e atualizadas. Depende, portanto, da existência de uma rede de informações ocupacionais.

A publicação da CBO 2002 representou um passo importante na direção preconizada. Ela constitui um instrumento imprescindível de organização do levantamento de informações, análise e divulgação de dados pela administração do Estado, além de contribuir para normalizar os critérios de prestação de informações do setor privado ao poder público. Para que consiga subsistir como uma ferramenta útil deve, contudo, acompanhar as mudanças do mercado de trabalho, que têm sido constantes e, nos anos recentes, aceleradas. Esse é o desafio do documento recém-dado a público.

Por seu caráter inovador, que se revelou em muitos aspectos do levantamento de dados sobre as ocupações, a tarefa de revisão da CBO foi sujeita a óbices cuja superação envolveu incontáveis decisões. $\mathrm{O}$ acerto ou não destas ficará evidente nos anos vindouros, pois os momentos futuros de revisão da $\mathrm{CBO}$ representarão oportunidades convenientes para eventuais correções. 


\section{NOTAS}

Versão preliminar submetida ao Comitê Científico do VIII Encontro Nacional da Associação Brasileira de Estudos do Trabalho, realizado em São Paulo em outubro de 2003.

1. Para uma descrição pormenorizada das instituições conveniadas e da pesquisa de modo geral, ver MTE/SPPE, 2002.

2. Uma análise oportuna de algumas dessas transformações, em âmbito mundial, pode ser encontrada em Castells, 1999.

3. Por tomar como referência a CIUO88, a CBO 2002 organiza as ocupações, em seu nível mais agregado de informações, em dez Grandes Grupos (GG), definidos segundo o nível de competência e similaridade nas atividades executadas. Na CIUO88 essas variáveis foram reunidas com base em quatro graus de escolaridade. Além da escolaridade, a CBO 2002 leva em conta, principalmente, o nível de complexidade das atividades requeridas para o exercício das ocupações (MTE, SPPE, 2002). Em decorrência deste procedimento, diferentemente da CIUO88, que atribuiu ao GG 9 o nível de competência 1 (não-qualificados), a nova versão brasileira não enquadra qualquer grupo no nível mencionado. Os GG descritos pela Fipe correspondem aos níveis 2 (GG 4, 5,7 e 9), 3 (GG3) e 4 (GG2). Assim como o documento internacional, a CBO 2002 não estabelece tal correlação para os GG 0 e 1, por abarcarem ocupações com níveis de competência heterogêneos.

4. Os treinamentos foram ministrados pelos professores Lawrence Coffin e Pierre Morin, ambos vinculados à Capra/CVA

5. Para uma relação completa das ocupações não contempladas na $\mathrm{CBO}$ 94 e incluídas na estrutura da CBO 2000, ver MTE/SPPE, 2002.

6. Tal afirmação não deve sugerir obviamente que a descrição das famílias ocupacionais mediante o método Dacum tem representatividade estatística. Os comitês foram formados segundo as regras estipuladas pelo método e basearam-se em princípios, fundamentalmente, qualitativos.

7. De modo não necessariamente continuado e com grau de envolvimento variado, participaram da Comissão representantes do HSBC Bank Brasil, Banco Mercantil de São Paulo, Banespa, Bradesco, Itaú, Real ABN AMRO S/A e Sudameris.

8. Foram consideradas famílias específicas do setor bancário: Diretores de Operações de Serviços em Instituição de Intermediação Financeira; Gerentes de Operações de Serviços em Instituição de Intermediação Financeira; Profissionais da Administração Econômico-Financeira; Profissionais de Comercialização e Consultoria de Serviços
Bancários; Corretores de Valores, Ativos Financeiros, Mercadorias e Derivativos; Técnicos de Operações e Serviços Bancários e Escriturários de Serviços Bancários, esta última integrada também pela ocupacão de Caixa de Banco, O rol das famílias transversais ficou formado pelas famílias: Diretores Gerais; Gerentes Administrativos, Financeiros e de Riscos; Gerentes de Tecnologia da Informação; Analistas de Sistemas Computacionais e Economistas.

9. É importante dizer que se trata de uma profissão predominantemente feminina, como se pôde observar no recrutamento dos painéis de especialistas, confirmando o que se verificou em pesquisas anteriores. (ver, por exemplo, Bianchi; Pastore, 1999).

10. Lei de Diretrizes e Bases da Educação Nacional, $n^{\circ}$ 9.394/96; art. 87 , parágrafo $4^{\circ}$ ).

11. O Conselho Federal de Fisioterapia e Terapia Ocupacional (Coffito) disponibilizou uma série de documentos que comprovam a inexistência "jurídica" dessa ocupação. Junto a esse dossiê, tendo por base a CBO 94, o Coffito solicitou alterações para a CBO 2002.

12. Resta saber se a atividade de supervisão de lavanderias pode ser enquadrada juntamente com outras ocupações de natureza semelhante. Afinal, trata-se de uma atividade administrativa, que guarda bastante semelhança com a atividade de supervisão em outros ramos de atividade.

\section{REFERÊNCIAS BIBLIOGRÁFICAS}

BIANCHI, AM.; PASTORE, J. Novas evidências acerca das ocupações no mercado de trabalho. Nova Economia, v.9 n.1, jul. 1999.

CASTELls, M. A sociedade em rede. Rio de Janeiro: Paz e Terra, 1999.

MTE/SPPE. Classificação Brasileira de Ocupações: CBO 2002. Brasília: MTE, 2002.

Nelson Hideiki Nozoe: Professor Assistente Doutor da FEA-USP.

Ana Maria Bianchi: Professora Titular da FEA-USP.

Ana Cristina Ablas Rondet: Economista, Pesquisadora da Fipe. 